\title{
MARGEANDO ARTIVISMOS GLOBALIZADOS: NAS BORDAS DO MUJERES AL BORDE
}

\author{
Glauco B. Ferreira \\ Universidade Federal de Santa Catarina
}

\begin{abstract}
Resumo: Este ensaio aborda as produções artísticas de um coletivo colombiano chamado Mujeres Al Borde e busca descrever algumas de suas atividades e as maneiras como produzem e articulam relações entre arte, ativismo e produção audiovisual, abordando aí gênero, sexualidade e questões étnico-raciais. O trabalho trata das relações transnacionais desse coletivo com um grupo queer ativista estadunidense, Queer Women of Color Media Arts Project, para a criação de seu próprio programa de treinamento cinematográfico, a Escuela Audiovisual Al Borde; reflete sobre as possibilidades de pensarmos sobre ativismo queer no contexto latinoamericano; e, por fim, analisa algumas das produções audiovisuais do Mujeres Al Borde, naquilo que compreendem como seu artivismo, neologismo que articula arte e ativismo. Enfocam-se as maneiras pelas quais esses coletivos produzem redes de colaboração transnacionais em contextos geopolíticos globalizados dissidentes, ao mesmo tempo em que buscam, através da relação que criam entre arte e política, promover transformação social e meios de expressão visual para comunidades $L G B T Q$, cultivando queer artivismos feministas no sul e no norte globais. Palavras-chaves: micropolíticas e movimentos LGBTQI contemporâneos; cinema, arte e gênero; queer ativismo latino-americanos; modos de globalização dissidentes.
\end{abstract}

\section{Introdução}

Uma característica que se destaca no trabalho comunitário e educativo que grupos queer of color realizam é justamente a iniciativa coletiva de solidariedade e cooperação,

Copyright @ 2015 by Revista Estudos Feministas.

1 "Queer Women of Color" no original em inglês poderia ser traduzido como "mulheres queer de cor" e demarca a preocupação em ressaltar as representações dos sujeitos envolvidos nas iniciativas de diversos movimentos sociais nos EUA, assinalando no contexto norte-americano, principalmente, os debates no âmbito do ativismo LGBTQ e dos feminismos não brancos a respeito das interseções entre gênero, "raça/etnicidade" e sexualidades, tomadas de forma aberta e não essencialista. As categorias queer e of color, inicialmente utilizadas como palavras e expressões acusatórias e/ou discriminatórias, são ali reapropriadas, ganhando significados renovados ligados ao empoderamento das comunidades e indivíduos aos quais eram dirigidas como ofensas, produzindo e denotando novas positividades e o reconhecimento de diferentes processos identitários entrecruzados através e além dessas categorias. Todas as traduções existentes neste ensaio - sejam estas traduzidas do inglês ou do espanhol - são minhas. 
que, em muitas ocasiões, cruza diferenças culturais, distâncias geográficas e, claro, histórias locais e particularidades de diferentes movimentos sociais. Esses esforços afinam-se através de discursos compartilhados e elaborados coletivamente na busca por algo que poderia ser reconhecido e construído como uma forma de comunidade e ativismo LGBTQ $^{2}$ transnacional, que ganha sua materialidade no sul e no norte globais, considerando-se as especificidades de cada contexto nacional. Um desses trabalhos de cooperação e solidariedade transnacional desenvolve-se entre dois coletivos lésbicos, trans, queer e feministas, o Mujeres Al Borde ${ }^{3}$ e o QWOCMAP, ${ }^{4}$ situados na Colômbia e nos Estados Unidos respectivamente. Esses são coletivos ativistas que, embora bastante diversos em suas atividades e composições, guardam também similaridades no que diz respeito às maneiras pelas quais cruzam e materializam práticas políticas, ativismo, arte e produção videográfica.

Conheci o trabalho do Mujeres Al Borde pelas parcerias transnacionais que esse coletivo nutre com o QWOCMAP, grupo feminista com o qual tenho trabalhado ${ }^{5}$ na pesquisa que realizo desde 2012 sobre ativismo, arte e comunidades queer of color na Baía de San Francisco, nos Estados Unidos. Além de iniciar contatos, por meio da internet, para viabilizar parte do meu campo com o QWOCMAP, pude acessar seus filmes e materiais de divulgação através do universo digital, realizando assim parte de minha pesquisa de campo a distância, num ambiente de interações virtuais bastante específicas, naquilo que considero um tipo de etnografia no ciberespaço, tal como já ressaltei em outra ocasião. ${ }^{6}$

É interessante considerar como certas interações não presenciais/virtuais podem ser tão significativas e interessantes quanto aquelas feitas em formatos de investigação social presenciais mais tradicionais. Nessas interações virtuais e depois, em forma presencial, pude também reconhecer as diversas parcerias que 0 QWOCMAP nutre com outros grupos, ONGs e organizações sem fins lucrativos, e uma delas, a relação com o Mujeres Al Borde, chamou especial atenção justamente pelos tipos de iniciativas criativas que esse coletivo fomenta na Colômbia e pelas maneiras pelas quais eles/as trabalham no universo virtual, utilizando plataformas de streaming de vídeo, seu website e as redes sociais como um modo de difusão e visibilidade para sua produção videográfica focada em gênero, sexualidades e artivismo.

Minha intenção aqui é criar uma narrativa que possa refletir e falar 'de perto' - ainda que nas 'margens', digamos assim - sobre algumas das atividades desses coletivos, sua interação e, mais especificamente, a respeito das iniciativas do Mujeres Al Borde, grupo no qual me focarei neste ensaio, que, embora seja um coletivo 'localizado' nas regiões

\footnotetext{
${ }^{2}$ A sigla "LGBT" sinaliza o agrupamento dos segmentos de lésbicas, gays, bissexuais e transgêneros. Recentemente, em âmbito internacional, principalmente, a letra " $Q$ " (representando os segmentos que se autodefinem Queers, ou Questionadores do binarismo de gênero, também denominados genderqueer e gender nonconforming) e a letra "I" (representando os segmentos denominados Intersexo) foram adicionadas à sigla "LGBT", resultando em "LGBTQl". No contexto deste artigo utilizarei a sigla LGBTQ.

${ }^{3}$ Numa tradução livre, o nome do coletivo colombiano Mujeres Al Borde poderia ser concebido tal como "Mulheres à margem", ou talvez mesmo, numa versão um pouco mais ousada, como mulheres "no limite" ou "nas beiras".

${ }^{4}$ A sigla corresponde à Queer Women of Color Media Arts Project, nome da organização sem fins lucrativos com a qual venho desenvolvendo meu trabalho de campo em San Francisco. Seu nome, caso traduzido, poderia ser algo tal como "Projeto de Mídia e Artes para Mulheres Queer de Cor".

${ }^{5}$ Este trabalho está partindo de análises iniciais realizadas no contexto de meu doutorado Antropologia Social, iniciado no ano de 2012 na Universidade Federal de Santa Catarina (UFSC). Algumas das questões aqui abordadas se fazem presentes no trabalho de campo e de análise que estou realizando durante os anos de 2013 e 2014, trazendo assim as reflexões preliminares que estão ainda em processo e que são sugeridas ao longo deste ensaio.

${ }^{6}$ Glauco FERREIRA, 2012, p. 68-86.
} 
tangenciais do meu próprio trabalho de campo junto ao QWOCMAP, ${ }^{7}$ torna-se um interessante exemplo de como poderíamos começar a pensar sobre as manifestações queer na América Latina e sobre relações políticas transnacionais entre coletivos LGBTQ em um contexto mundial globalizado. $^{8}$

\section{Relações queer feministas globalizadas e dissidentes}

Aqui então tentarei 'falar de perto' desses grupos, margeando falas e conversações, além de outros dados de campo (dentro e fora do universo online), tratando de evidenciar os modos pelos quais se articulam suas iniciativas de artivismo ao focar, especialmente no caso do Mujeres Al Borde, nos processos identitários e de subjetivação que desenvolvem através dos seus filmes, na busca por promover transformação social através de criações artísticas. Num contato que se iniciou em 2010, esses dois coletivos vêm nutrindo parcerias que extrapolam a simples admiração e identificação pelo tipo de trabalho que realizam no terreno das artes. Essas coligações se amplificam nas similaridades e nas maneiras pelas quais eles/as coincidem na junção de atividades nem sempre vistas como complementares ou, até mesmo, diversas vezes, vistas como exclusivas, tais como a arte e política.

O QWCMAP desenvolve, desde o começo da década de 2000 , um tipo de artivismo cinematográfico que reúne comunidades imigrantes e queer of color na Baía de San Francisco, buscando expandir sua atuação em diversas regiões da Califórnia e, mais recentemente, em outras partes do mundo, tais como Colômbia e México. Ao realizar um festival de cinema anual e também treinamentos de novos cineastas e videomakers em workshops gratuitos, o QWOCMAP trata de cultivar diversas parcerias com organizações, coletivos e grupos focados nas questões pertinentes às comunidades of color, centrando principalmente em organizações "irmãs" que também enfoquem debates sobre gênero, sexualidade e pertencimento étnico e racial. Nesses workshops, que duram em média 16 semanas, além de sessões em laboratórios de edição digital de imagens, os participantes passam por treinamento para que aprendam, com diferentes aprofundamentos, a criarem, escreverem, dirigirem e editarem filmes de curta metragem em que diferentes recursos são utilizados como dinâmicas de envolvimento e aprendizagem. ${ }^{9}$

No caso do Mujeres Al Borde, as atividades se desdobram em criações cênicas e também videográficas que abordam questões pertinentes às comunidades de mulheres,

\footnotetext{
${ }^{7}$ Cabe aqui agradecimento especial à Trinh T. Minh-há, que estava supervisionando minhas atividades como Visiting Scholar in Gender \& Women's Studies na University of California at Berkeley (UC Berkeley), como parte de meu estágio doutoral sanduíche, com bolsa de pesquisa CAPES/PSDE, ao mesmo tempo que desenvolvia minha pesquisa de campo durante o ano de 2014.

${ }^{8} \mathrm{~A}$ teórica e cineasta feminista pós-colonial Trinh T. Minh-há problematiza os espectros colonialistas na produção de conhecimentos, seja artísticos, seja científico/acadêmicos, propondo assim "falar de perto ao invés de falar sobre" (talking nearby instead of talking about) determinado contexto de interação, seja para a produção de um filme documentário, em criações visuais, seja numa crítica epistemológica à antropologia, no contexto de encontros etnográficos e em suas resultantes etnografias. Ao trabalhar com formas de linguagem indireta, 'falar de perto' sugere que não se 'objetifique', que não se aponte para um 'objeto' como se ele estivesse distante do sujeito falante, daquele/a que cria uma narrativa, ou mesmo que se esteja 'Iongínquo' nos termos dos lugares de fala nos quais essas narrativas são engendradas. Seriam assim tipos de narrativas ou falas que refletem sobre as condições de sua produção, achegando-se de seu objeto de reflexão de maneira bastante próxima, sem que essa proximidade, no entanto, tome ou clame o lugar do próprio objeto de investigação, criando, ao mesmo tempo, uma forma de narrativa vívida e não mera ilustração de um outro processo (também vívido) de interação social e criação artística. Conferir T. Minh-Ha TRINH, 1991 e T. Minh-há TRINH e Nancy N. CHEN, 1992.

${ }^{9}$ FERREIRA, 2012, p. 71.
} 
homens, pessoas trans e intersexo que não se conformam às limitações e disciplinamentos em termos de gênero e sexualidade, tratando também de pertencimentos culturais e étnicos latino-americanos. O grupo, que teve o começo de suas atividades em 2001, destaca, em um de seus manifestos mais recentes, a diversidade do coletivo quando é composto por "lésbicas, bissexuais, transexuais, pansexuais, homossexuais, heterodissidentes, intersex, queers, anormais e hermonstros/as", na qual o desejo de liberação, criação e os processos de desejo são valorizados. ${ }^{10}$ Essa compreensão local adota uma das perspectivas nos debates feministas contemporâneos que incorpora em suas elaborações políticas o gênero e as sexualidades como dispositivos discursivos, conformando corpos e subjetividades. Gênero e sexualidades, nesse caso, mesmo que sejam categorias em si mesmas, são também interdependentes, pois o que se propõem ali é borrar as fronteiras dicotômicas entre o 'masculino' e o 'feminino' e entre o 'heterossexual' e o 'homossexual', "pensando nas práticas sexuais e a sexualidade em conjunto com as diferenças de gênero, que seriam negociadas na contemporaneidade através dos processos identitários e de desejo". ${ }^{11}$

Esses dois grupos cruzam-se pelo tipo de parcerias que buscam manter entre diversas organizações em níveis locais e transnacionais, de maneira que sua interação inicial ocorreu em função da participação de ambos em fóruns feministas transnacionais. Em uma de minhas conversas com Kebo Drew, integrante do QWOCMAP, ela descreveu os primeiros contatos entre os dois coletivos na Cidade da Guatemala em 2010, no VII Encontro Lésbico Caribenho e Latino-Americano, contexto no qual a identificação inicial em termos políticos e artísticos entre eles/as deu origem à vontade de estabelecer parcerias posteriores. Após esse primeiro contato, a parceira frutificou e, no aprofundamento desse intercâmbio, o coletivo estadunidense, na figura de Liliana Hueso, integrante do QWOCMAP naquele momento, auxiliou na criação de um módulo de treinamento para a produção de audiovisuais próprios do Mujeres Al Borde, num contexto em que o coletivo latino-americano já desenvolvia, desde longa data, produções teatrais que envolviam questões de gênero, sexualidade e comunidades marginalizadas em Bogotá.

Assim, inspirados/as no programa de treinamento cinematográfico do coletivo estadunidense, surgiu a Escuela Audiovisual Al Borde, iniciativa na qual o coletivo colombiano busca intencionalmente trabalhar adaptando sua experiência anterior de artivismo cênico na Escuela Queer Teatro de las Aficionadas, um programa de treinamento cênico que dura de nove a doze meses, para a elaboração de suas próprias criações e treinamentos em cinema e vídeo. Muitos de seus filmes trabalham com dinâmicas coletivas e individuais que partem das ideias relacionadas aos limites e às margens, 'locais' simbólicos e materiais nos quais essas sexualidades e suas expressões de gênero se configuram, numa abordagem aberta que busca trabalhar com o que surge a partir das experiências individuais dos/as participantes, criando novas palavras e imagens como meios de nomear e materializar experiências, processos identitários e de desidentificação. Em seu web site,,$^{12}$ o coletivo advoga pela necessidade de tornar visível o que sempre esteve invisível, tratando de criar suas próprias imagens, problematizando violências de gênero e dinâmicas heteronormativas limitantes. Os frutos do programa de treinamento que eles/as desenvolveram resultaram num convite estendido ao Mujeres Al Borde para a participação no XII Encontro Feminista Caribenho e Latino-Americano que ocorreu em Bogotá em 201 1, do qual o QWOCMAP também participava, possibilitando que os dois coletivos estreitassem mais ainda a relação que vinham nutrindo a distância e em encontros ocasionais em contextos de ativismos feministas.

\footnotetext{
${ }^{10}$ Ana LUCHX, 2014.

"Judith BUTLER, 2002, p. 335. Conferir também Gayle RUBIN e Judith BUTLER, 2003.

${ }^{12}$ Seu endereço eletrônico é http://www.mujeresalborde.org/.
} 
A criação desses filmes no contexto do Mujeres Al Aborde se expandiu ao longo dos anos em criações que são realizadas durante um treinamento de dois meses, nas quais os/ as participantes criam documentários autobiográficos ao mesmo tempo em que se envolvem nas produções de colegas também em treinamento. Visando um artivismo que transpassa fronteiras, eles/as querem criar vínculos entre os/as participantes ao gerar espaços para o compartilhamento de histórias e processos de intercâmbio cultural, de desejos e de identificações sexuais, de gênero e étnico-raciais, além de diferentes processos de inserção no ativismo e nas práticas de criação artística quando se relacionam com militantes colombianos e também com participantes de outros países latino-americanos. No ano de 2013, a produção de cinema do Mujeres Al Borde já tinha sido exibida em diversos festivais de cinema, tais como o Femina, festival sediado no Rio de Janeiro, e também o Barcelona Gay and Lesbian Film Festiva, realizado na Espanha.

A parceria entre o QWOCMAP e o coletivo colombiano também teve continuidade ao passo que a produção cinematográfica do Mujeres $A /$ Borde pôde integrar pela primeira vez a programação da oitava edição do Queer Women of Color Film Festival em 2012, festival de cinema anual organizado pelo QWOCMAP para exibição de sua própria produção videográfica realizada nos workshops e que conta também com curadoria de filme de outros/as diretores/as queer of color com foco em gênero, sexualidades e comunidades marginalizadas em termos étnicos. Com financiamento da fundação Astraea, ${ }^{13}$ foi possível que Claudia Corredor e María Cristina Rodríguez, integrantes do Mujeres Al Borde, participassem presencialmente do festival de cinema do QWOCMAP na Califórnia naquele ano, levando consigo sete filmes documentários autobiográficos ${ }^{14}$ produzidos em 2011 em Bogotá e em Santiago do Chile. Conforme narram em seu site, ${ }^{15} \mathrm{a}$ experiência foi muito interessante pelas já citadas afinidades entre os dois coletivos, em relação ao que eles/as chamam de "um trabalho muito conectado ao seu artivismo audiovisual" e, simultaneamente, pelas dinâmicas do próprio festival, onde as trocas realizadas são também maneiras de construir comunidades transnacionais palpáveis.

Com filmes dos/as artivistas Fer, Jimena, Andrea, Damian, Claudia, Muñeka y Michel, - coletivo colombiano parece privilegiar as histórias de vidas dos/as participantes e criadores/as em suas produções, possibilitando acesso gratuito aos meios técnicos de produzir esses filmes. Com um formato de festival de cinema que privilegia a interação da comunidade que agrupa, o QWOCMAP possibilita que os/as diretores/as dos filmes que exibem tenham espaço para conversação com a audiência, detalhando, através do formato de perguntas e respostas, o processo de criação dos filmes. Nas narrativas das integrantes do coletivo colombiano, a participação no festival e o debate com a audiência possibilitaram que se produzissem processos de identificação da audiência presente com as histórias retratadas nos filmes, permitindo que se visibilizassem desde pontos de vista variados, situados no sul global, outras realidades e processos identitários de gênero,

\footnotetext{
${ }^{13}$ Astraea,Lesbian Foundation for Justice é uma organização filantrópica fundada em 1977 que trabalha na defesa de direitos $L G B T Q 1$ em diversas partes do mundo. Como organização feminista multirracial e multiclassista, o objetivo da fundação se define no esforço de reunir finanças para coletivos e ações voltados especialmente às lésbicas e mulheres de cor, visando construir conexões entre ativistas, doadores e a comunidade LGBTQ ao redor do mundo. A fundação, cujo site é http://www.astraeafoundation.org/,também financiou os programas de treinamento do Mujeres Al Borde ao longo dos anos. Neste ano, o coletivo também contou com o apoio financeiro do Global Fund for Women.

${ }^{14} \mathrm{O}$ trailer da Escuela Audiovisual Al Borde, que reúne parte da produção audiovisual de 2011 exibida no festival estadunidense, está disponível no seguinte vídeo: http://bit.ly/1AT7Aic.

${ }^{15}$ Numa postagem em seu website, em julho de 2012, eles/as narram o processo de participação no festival e outros detalhes do intercâmbio entre os dois coletivos naquela ocasião: http://bit.ly/XC49gJ.
} 
sexualidade e étnico-raciais. Enfatizando simbólica e literalmente o ato de cruzar fronteiras, geográficas e/ou culturais, ao habitá-las e recriá-las, o Mujeres Al Borde se mostrou aberto ao convite de compartilhamento de suas histórias criadas desde as "bordas", nutrindo, em conjunto com o QWOCMAP, "novas conexões de cumplicidade e afeto que vão mais além das fronteiras do idioma ou das fronteiras simbólicas e materiais entre 'norte' e 'sul'."16

Naquele ano, também foi possível realizar um painel de debates entre diferentes ativistas e criadores do qual participaram as integrantes do coletivo colombiano, Claudia Corredor e María Cristina Rodríguez, contando também com Mónica Énriquez-Énriquez, integrante da fundação Astraea e cineasta curadora do QWOCMAP, e Elisa Diana Huerta, ativista queer e anteriormente coordenadores/as dos festivais do QWOCMAP em sua quarta e quinta edições. Nesse painel, os/as participantes abordavam temáticas em torno da interseccionalidade e das possibilidades de construção de alianças LesbiTrans feministas entre América Latina e América do Norte, assuntos centrais da edição daquele festival, além das discussões sobre as uniões civis. Os filmes dos/as criadoras do coletivo colombiano, reunidos na sessão principal do festival naquela ocasião, chamada Unfenced/Sin Valla, ${ }^{17}$ abordavam questões relacionadas às fronteiras geográficas e simbólicas, trabalhando diferentes maneiras em que limites são impostos às expressões das sexualidades. A parceria entre os dois coletivos continuou após essas intensas trocas durante 2012 , com parte da produção do coletivo colombiano apresentada também na décima edição do festival em 2014 , tendo como cerne questões relativas à justiça ambiental para as comunidades queer of color dentro e fora dos EUA. Nessa edição do evento, as produções exibidas pelo Mujeres Al Borde foram filmes que abordavam as lutas de comunidades rurais na Colômbia na sua relação de violência e resistência com os grupos paramilitares e com o governo colombiano.

A importância e potência das 'margens' nessas narrativas é crucial para entendermos a retórica a partir da qual são realizados muitos desses filmes e vídeos. Tal como aponta Mónica Énriquez-Énriquez, ${ }^{18}$ ativista colombiana que faz parte da fundação Astraea, imigrante nos Estados Unidos e também cineasta curadora do QWOCMAP, as experiências do grupo ativista colombiano narravam de maneira documental histórias de resistência e lutas para autodeterminação de pessoas queer e não binárias em termos de gênero e sexualidade e que ressaltam de maneira presente seus pertencimentos étnicos e raciais. Narradas em primeira pessoa, suas impressões sobre o painel de debates do qual participou, com as integrantes do Mujeres Al Borde na décima edição do festival de cinema realizado pelo coletivo estadunidense, possibilitaram que se fizessem visíveis as maneiras pelas quais os filmes do coletivo colombiano abordam histórias que geralmente estão invisíveis nas mídias mainstream. Evidenciando o poder e os significados das conexões transnacionais entre os dois coletivos naquela ocasião, ela nota como as formas e os usos da fantasia e criatividade presentes nessas imagens buscam questionar certas construções narrativas para imaginar futuros e vidas alternativas ao interrogar simultaneamente os paradigmas masculinistas, homonormativos e brancos e denotar, como sugerem alguns autores, "que é precisamente nas margens, em relação com sexualidade e desejo, que as críticas mais poderosas e indispensáveis sobre formações e noções dominantes de nação, diáspora e sexualidade tomam lugar." 19

\footnotetext{
${ }^{16}$ Ana LUCHX, 2012.

17 O título do painel poderia ser traduzido literalmente como "Sem cercas". Poderíamos pensar em sentidos mais abrangentes tais como "sem limites", "sem grades" ou mesmo "sem fronteiras".

${ }^{18}$ Mónica ÉNRIQUEZ-ÉNRIQUEZ, 2012.

${ }^{19}$ Gayatri GOPINATH, 2005, p. 28.
} 
Uma das imagens que mais caracterizam a Escuela Audiovisual Al Borde é o seu logo, que representa um/a videomaker transgênero vestindo gravata e saltos altos. Para Mónica, este/a videomaker transgênero seria capaz de metaforicamente cruzar fronteiras nacionais e de gênero, capturando magia, fantasia e sobrevivência. Numa compreensão que concebe transformação social em termos coletivos e individuais, Mónica observa que o tipo de criação ali acionada e as redes estabelecidas entre esses coletivos

\begin{abstract}
[...] utilizam-se do riso e do afeto para construir pontes, formular críticas, protestar contra opressão institucional, desconstruir gêneros e criar fortes redes para mudança social. [...] [Criar filmes nas 'margens', seja na Colômbia, no Chile ou nos Estados Unidos se torna, muitas vezes, uma das únicas] formas de sobreviver quebrando isolamentos, tanto em nível local e global. Não podemos mais nos dar ao luxo de trabalhar sem nos unirmos em colaboração. Pessoas LGBTQI of color vivendo e sobrevivendo nos Estados Unidos devem se conectar com pessoas LGBTQI vivendo e sobrevivendo no leste global e no sul global e vice-versa. Desta forma, podemos trocar estratégias, construir amizades, traduzir nossas diferentes experiências, celebrar diferença, e, como resultado, criar novas possibilidades. ${ }^{2}$
\end{abstract}

Nessa compreensão, podemos falar em margens, considerando aí as bordas, os limites e as fronteiras de todas as ordens e incluindo reflexões sobre o que seja o 'centro' e o que seja a 'periferia', se consideramos que exista um 'centro', tomado e constituído sempre como referencial. Considerar esses processos identitários e as imagens criadas nas iniciativas desses coletivos, muitas vezes consideradas como "periféricas" ou mesmo "marginais", somente se torna possível se passarmos também a questionar os lugares e espaços de "marginalização". Tal como aponta Prathiba Parmar, ${ }^{21}$ ao produzir filmes que lidam com essas diferenças, esses sujeitos encaram desafios constantes na luta por desafiar certas instituições sociais e culturais canônicas, que buscam repetidamente fazer com que se acredite, em função dessas mesmas visíveis diferenças, que essas individualidades sejam um 'Outro' e, assim, também aqueles/as 'marginais', mesmo que ao longo de sua conformação subjetiva esses sujeitos nunca tenham pensado em si mesmos em termos de marginalidade ou mesmo como o "Outro" exotizado pelas potências imperialistas, tomadas tais como se fossem o "centro" a princípio.

\title{
Modos de subjetivação, artivismo e transformação social
}

Na Escuela Audiovisual Al Borde, torna-se presente a vontade de contar histórias em primeira pessoa que abordem as vidas dos/as criadores/as, tomando os meios audiovisuais e o vídeo como 'cúmplices' nesse processo criativo. Seus trabalhos buscam transparecer, através das mídias visuais, as maneiras pelas quais eles/as realizam seu artivismo contrassexual $^{22}$ na América do Sul, em exercícios de compartilhamento de experiências micropolíticas ${ }^{23}$ que materializem transformação social. Lidando muitas vezes com discursos sociais que patologizam expressões de sexualidades que colocam em xeque o binarismo de gênero e a heterossexualidade compulsória, esses/as artivistas criam formas de produzir cinema respondendo às representações que excluem os corpos ditos 'diferentes', buscando "reconhecer os diversos sexismo e heteronormatividades, a patologização do desejo, atrevendo-se a criar outras maneiras de viver a sexualidade, que fazem o prazer visível, e que 'escapam' das normas e convencionalismos." ${ }^{24}$

${ }^{20}$ ÉNRIQUEZ-ÉNRIQUEZ, 2012, grifo da autora.

${ }^{21}$ Pratibha PARMAR, 1993, p. 4-5.

22 Beatriz PRECIADO, 2002 e 2011.

${ }^{23}$ Conferir Félix GUATTARI e Suely ROLNIK, 1986, p. 53-55

${ }^{24}$ Aritza Álvarez M*ARA, 2014. 
Como dito anteriormente, a circulação da produção videográfica do Mujeres $A l$ Borde se dá através da exibição em diversos festivais de cinema e também ao longo do intercâmbio com outros grupos ativistas; mas não se restringe somente a esses espaços ou mesmo aos formatos mais reconhecidos de produção cinematográfica; se expressa simultaneamente no modelo contemporâneo de produções visuais para a internet, tais como as web séries, transmitidas por meio de streaming de vídeo. Esse é o caso da web series por eles/as chamada de Artivismos: La Imagin-acción del Deseo, ${ }^{25}$ desenvolvida pela Al Borde Producciones, divisão de produção do coletivo colombiano. Nessa web serie, composta até o momento de cinco diferentes vídeos documentários, observamos uma das maneiras pelas quais o coletivo realiza seu artivismo, ao registrar sujeitos envolvidos em artivismos variados, que abordam gênero, sexualidade e questões étnicas e raciais em seu próprio trabalho de invenção.

Dois desses filmes chamam especial atenção pelo fato de terem sido produzidos no interior de fóruns ativistas feministas, tratando-se de trabalhos dirigidos e produzidos durante o evento Venir Al Sur - I Encontro LesBitransInter Feminista da América Latina e do Caribe, que ocorreu no Paraguai, na cidade de Assunção em 2012. Num desses filmes, intitulado Artivismos 3: los muchos cuerpos de um solo cuerpo, al desnudo, ${ }^{26}$ observamos uma das performances da artivista e antropóloga colombiana Lillith Natasha Border Line, na qual somos simultaneamente confrontados com os processos identitários sugeridos por suas narrativas, ela posiciona-se como sujeito que diversas vezes escapa das definições e siglas, apontando para o que poderíamos considerar como um processo de subjetivação queer e resgatando, em certo sentido, as origens trans dessa categoria em sua elaboração inicial.

Uma das questões mais recorrentes nesses documentários são as formas pelas quais esses sujeitos compreendem suas atividades artísticas e políticas tais como ações que estão profundamente imbricadas. ${ }^{27}$ É o caso da poeta e performer argentina Susy Shock, que aborda em sua música e poesia, a sexualidade, o gênero e a etnicidade a partir de sua posição como pessoa transgênero, buscando referenciar suas experiências trans aos fluxos e transformações atribuídos a Pacha Mama, a deusa mãe dos povos originários e indígenas latino-americanos. Suzy reverencia Pacha Mama buscando defini-la como um todo nem sempre classificável e, que por isso mesmo, é trans, concebido por ela, em suas palavras, como algo em "movimento, recriando-se, fusionando-se, juntando-se, revolvendo e somando, jogando" com um conceito ligado à terra, numa sinalização de seus pertencimentos étnicos e culturais. Nas palavras de Susy, que é personagem principal do vídeo Artivismos 3: Sudaca, Trans y Artivista - Susy Shock Letal, ${ }^{28}$ a outra criação audiovisual também produzida no encontro ocorrido em Assunção em 2012, a arte "é algo sempre político, pois se trata também de um modo comunicacional absoluto, de construção de vínculos, de construção de símbolos, de afirmação ou de desconstrução de símbolos e não há nada mais político do que isso."29

Em muitas criações audiovisuais do coletivo colombiano também se denotam as maneiras pelas quais pessoas LGBTQ experimentam violências institucionais, físicas, interpessoais, psicológicas, especialmente na esfera pública. No contexto colombiano são

\footnotetext{
${ }^{25}$ Os vídeos podem ser assistidos no endereço eletrônico http://bit.ly/1s8Qnel.

${ }^{26}$ Acesse o vídeo, disponível em http://vimeo.com/58178861.

${ }^{27}$ Essa é uma questão que também é recorrente em Artivismos 1: diálogos entre travestis, outro filme da web serie, produzido em 2011 e disponível em http://bit.ly/1y4BhsG

${ }^{28}$ Acesse o vídeo disponível em http://vimeo.com/59183248.

${ }^{29}$ Essa narrativa faz parte do documentário disponível em http://vimeo.com/59183248.
} 
notórias algumas políticas ultraconservadoras nas quais pessoas queer e LGBT são os principais alvos de violência, corporificada de forma nefasta nas chamadas 'campanhas de limpeza social', ${ }^{30}$ "baseadas naquilo que se compreende como desvios em termos gênero e sexualidade, liderado por organizações paramilitares que diversas vezes são auxiliados pelos militares"31 e pelo governo.

Trabalhando com esses/as artivistas através de situações muitas vezes difíceis, o Mujeres Al Borde pode instruir e materializar maneiras pelas quais o pessoal pode ser coletivo e simultaneamente político, treinando novos criadores para a invenção de imagens em movimento e também de 'modos de constituição de subjetividade', no que Michel Foucault ${ }^{32}$ chama de regimes de subjetivação e define como os "diferentes modos pelos quais, em nossa cultura, os seres humanos se tornaram sujeitos", ${ }^{33}$ considerando aí as diferentes 'posições de sujeito' que podem ser configuradas e ocupadas. As maneiras de produzir transformação social tomam aqui a forma do que eles/as chamam de artivismo, prática política e de criação que visa potencializar e visibilizar os processos de subjetivação e as posições de sujeitos transfigurados. Na junção das palavras "arte" e "ativismo", eles/as desenvolvem este neologismo híbrido, "artivismo", denotando que ali fazer artístico e prática política são atividades indissociáveis, delineadas no interior dos trabalhos criados para o universo virtual. Suas iniciativas poderiam ser chamadas de queer artivismos digitais, que significam, na definição de alguns autores, ${ }^{34}$ tipos de criações visuais e estéticas "realizadas por indivíduos que articulam e enxergam uma relação orgânica entre arte e ativismo", gênero e sexualidade, combinando influências estéticas a partir dos feminismos não brancos e das discussões queer.

Em muitos aspectos, essas produções, que se originam no interior de movimentos sociais, extrapolam as fronteiras do que pode ser pensado como 'arte' por circuitos institucionalizados ${ }^{35}$ no universo das artes visuais, aquele tipo de arte que geralmente é visto em museus, galerias e espaços tipicamente 'artísticos'. Em algumas discussões recentes a respeito da produção de arte contemporânea, alguns pesquisadores no $\mathrm{Brasi}^{36} \mathrm{e}$ em outras partes do mundo ${ }^{37}$ têm denominado essas iniciativas pelos nomes de 'arte relacional', 'arte colaborativa', 'arte participativa' ou, algumas vezes, 'arte pública de novo gênero', num esforço crítico de elaboração teórica sobre essa produção artística. Essas tendências apontam para

[...] a superação do paradigma da autonomia da arte em detrimento de procedimentos engajados [...] no sentido de viabilizar relações na esfera da vida, [...] em que os espaços a serem ocupados já não são necessariamente os institucionais, [pois] a arte ocupa o espaço público, [...] resistindo e atuando coletivamente. ${ }^{38}$

Pensar em novos processos artísticos de criação, marcados por coletividades e por dimensões públicas e polêmicas da vida social, parece ser uma das maneiras que o coletivo colombiano encontra para expressar demandas coletivas que nem sempre encontram espaço para se materializar. Essas propostas pressupõem uma ampliação das discussões sobre a

\footnotetext{
${ }^{30}$ COLOMBIA DIVERSA, 2013, p. 11-12.

${ }^{31}$ ÉNRIQUEZ-ÉNRIQUEZ, 2012.

32 Michel FOUCAULT, 1984.

${ }^{33}$ FOUCAULT, 1995 p. 231.

${ }^{34}$ Chela SANDOVAL e Guisela LATORRE, 2008, p. 82. Conferir também Chela SANDOVAL, 2002.

${ }^{35}$ Alfred GELL, 2001.

36 José KINCELER, 2009; Mariana NOVAES, 2012; e Marcelo WASEM, 2012.

${ }^{37}$ Nicolas BOURRIAUD, 2009

${ }^{38}$ NOVAES, 2012 , p. 66.
} 
noção de "arte pública", num tipo de arte que está profundamente relacionada à esfera pública, naqueles que são processos de transformação, conflito e disputas no interior de contextos sociais bastante definidos. Numa mudança de perspectiva no modo como se encaram expressões artísticas conectadas à esfera pública, William. J. T. Mitchell, ${ }^{39}$ historiador e teórico estadunidense das artes visuais, propõe 'ampliação' e aprofundamento no modo como concebemos a esfera pública, levando igualmente a uma ampliação de escopo naquilo que é considerado como "arte pública" no interior dos debates historiográficos e teóricos sobre a arte contemporânea. Refletindo de forma semelhante, Susanne Lacy, ${ }^{40}$ artista e crítica de arte estadunidense, sugere a expressão 'arte pública de novo gênero' (new genre public arf), considerando aquelas práticas artísticas nas quais o engajamento direto dos artistas proponentes e dos participantes, eles mesmos, nessa relação, tornados também artistas, criam possibilidades de interagir e comunicar questões prementes para todos aqueles envolvidos, produzindo afinidades através de dispositivos relacionais que provocam encontro, compartilhamento de experiências e possibilidades de mudança social - processos nos quais as relações estabelecidas são os próprios objetos e materiais artísticos que constituem fontes para a criação visual e poética.

Aqui os dispositivos relacionais se tratam da própria Escuela Audiovisual Al Borde, que produzem imagens em movimento e materializam questões pertinentes à esfera pública em questões profundamente relacionadas às vidas das pessoas queer e trans na América Latina, principalmente na maneira como essas pessoas são tratadas e vistas no espaço público e nas relações de resistência que desenvolvem para responder a tais situações. As proposições artivistas do Mujeres Al Borde pressupõem-se como ambientes de reunião e elaboração sobre o espaço e a esfera pública, ambientes nos quais se encontram maneiras de resistir e contrapor-se a um contexto no qual a própria aparição e "aparência pública de pessoas queer e trans são diversas vezes punidas com violência legais e ilegais." ${ }^{41}$ Nesses ambientes de criação artística visual, constituídos como

[...] assembléias por pessoas trans e queer, a reivindicação feita é muitas vezes de que as ruas devem estar a salvo da polícia, que é cúmplice em ações criminais, especialmente nas ocasiões em que a polícia apóia regimes criminosos ou quando por exemplo, a própria polícia comete os crimes contra minorias sexuais e de gênero. ${ }^{42}$

Esse é um tipo de produção artística que se volta muito mais para as necessidades coletivas e individuais das comunidades, a partir e através das quais essa mesma produção tem sua origem, e que, ainda que também se insira e dependa dos circuitos institucionais para sua circulação, tem sua potência ativada de forma mais vívida quando realizada em comunidade, na forma de interação e criação de significados que os próprios sujeitos criadores/espectadores dão às imagens que produzem, desmantelando "os dispositivos políticos que produzem diferenças de classe, raça, gênero e sexualidade e feminismo, criando uma plataforma artística e política para a invenção de um futuro comum." ${ }^{43}$ Aqui, essas criações também poderiam ser consideradas como uma espécie de arte pública, pois discutem as maneiras pelas quais os/as participantes dos treinamentos e os próprios vídeos e

${ }^{39}$ William J. T. MITCHELL, 1992, p. 2. Agradeço à sugestão da Dra. Rosa Blanca Cedillo no que diz respeito a essa referência teórica e em parte das reflexões sobre a esfera pública presentes neste trecho do ensaio. Cabe também a ela um "obrigado" mais extensivo em decorrência de sua abertura, pela interlocução e pelo convite, à reflexão sobre as questões aqui esboçadas.

${ }^{40}$ Suzanne LACY, 1995, p. 19.

41 Judith BUTLER, 2012, p. 119.

42 BUTLER, 2012, p. 19

${ }^{43}$ Beatriz PRECIADO, 2007.

216 Estudos Feministas, Florianópolis, 23(1): 207-218, janeiro-abril/2015 
filmes do Mujeres Al Borde lidam com a recepção e as reações negativas frente às suas sexualidades em contexto público, realizando, assim, em sua exibição em espaços específicos para produção cinematográfica, nos intercâmbios dessa produção com grupos em outras partes do mundo, na veiculação pela internet e na própria criação dos vídeos, uma maneira de intervir criticamente em relações sociais na esfera pública, visando transformação social.

\section{Referências}

ARTIVISMOS 3: Sudaca, Trans y Artivista - Susy Shock Letal. Direção de Claudia Patricia Corredor com auxílio de Aritza M*ARA. Realizado em Assunção, Paraguai. Bogotá: Mujeres Al Borde Producciones, $2012.8 \mathrm{~min}$.

ARTIVISMOS 4: los muchos cuerpos de um solo cuerpo, al desnudo. Direção de Claudia Patricia Corredor com auxílio de Aritza M*ARA. Realizado em Assunção, Paraguai. Bogotá: Mujeres Al Borde Producciones, 2012. 8 min.

BOURRIAUD, Nicolas. Estética) relacional.) São Paulo: Martins Fontes, 2009.

BUTLER, Judith. "Bodies in alliance and the politics of the street." In: MCLAGAN, Meg; MCKEE, Yates. Sensible politics: the visual culture of nongovernmental activism. New York: MIT Press, 2012, p. 117-137.

Cuerpos que importan - sobre los limites materiales y discursivos del "sexo". Buenos Aires: Paidos, 2002.

COLOMBIA DIVERSA. Impunidad sin fin: informe de derechos humanos de lesbianas, gay, bisexuales y personas trans en Colombia, 2010 - 2011. Bogotá, 2013. Disponível em: $<$ http://bit.ly/1 owyW8u > . Acesso em:3 jul. 2014.

ENRÍQUEZ-ENRÍQUEZ, Mónica. 8th Annual Queer Women of Color Media Arts Project Film Festival. Blog da Astraea - Lesbian Foundation for Justice. [S.I.], 20 June 2012.Disponível em: <http://bit.ly/1ABAPGp>. Acesso em: 20 jul. 2014.

FERREIRA, Glauco. "QWOCMAP: (auto)representações de mulheres queer e de cor e sua produção audiovisual nos EUA". Revista Ártemis, v. 14, p. 68-86, ago./dez. 2012.

FOUCAULT, Michel. História da sexualidade II: o uso dos prazeres. Rio de Janeiro: Graal, 1984.

"O sujeito e o poder". In: RABINOW, Paul; DREYFUS, Hubert. Michel Foucault. Uma trajetória filosófica. Para além do estruturalismo e da hermenêutica. Rio de Janeiro: Forense Universitária, p. 231-235 1995.

GELL, Alfred. "A rede de Vogel, armadilhas como obras de arte e obras de arte como armadilhas". Arte e Ensaios:Revista do Programa de Pós-Graduação em Artes Visuais, Rio de Janeiro, ano VIII, n. 8, p. 174-191, 2001.

GOPINATH, Gayatri. Impossible desires: queer diasporas and south asian public cultures. Durham: Duke University Press, 2005.

GUATTARI, Félix; ROLNIK, Suely. Micropolíticas: cartografias do desejo. Petrópolis: Vozes, 1986.

KINCELER, José. "O processo criativo de 'vinho saber' - arte relacional em sua forma complexa", In: MARTINS, Pedro (Org.). Território esociabilidade. Florianópolis: PEST, 2009, p. $115-127$.

LACY, Suzanne. Mapping the terrain: new genre public art. Seattle: Ed. Bay Press, 1995.

LUCHX, Ana. Estreno Al Borde en San Francisco!Website do Mujeres Al Borde. 4 jul. 2012. Disponível em: <http://bit.ly/XC49gJ>. Acesso em: 10 jul. 2014.

. Manifiesto Al Borde - nuestros cuerpos y deseos territorios de paz!Website do Mujeres Al Borde. 5 jul. 2014. Disponível em: <bit.ly/1 nGSelp>. Acesso em: 15 jul. 2014.

M*ARA, Aritza Álvarez. Cine Al Borde, una peli que nos dejó mucho que desear! Website do Mujeres Al Borde. 28 abr. 2014. Disponível em: <http://bit.ly/1 tUJjGT>. Acesso em: 25 jul. 2014. 
MITCHELL, William J. T. (Ed.). Art and the public sphere. Chicago: University of Chicago Press, 1992.

NOVAES, Mariana. "Sistemas de arte participativa: apontamentos sobre um espaço praticado". Arte e Ensaio, Rio de Janeiro, v. I, n. 24, p. 64-75, ago. 2012.

PARMAR, Pratibha. "That moment of emergence". In: GEVEN, Marthe; PARMAR, Pratibha; GREYSON, John. Queer looks: perspectives on lesbian and gay film and video. New York:Routledge, 1993, p. 03-11.

PRECIADO, Beatriz. Manifiesto contra-sexual. Madrid: Opera Prima, 2002.

. "Mujeres en los márgenes". El País, Madrid, 13 enero 2007. Disponível em: <http:// bit.ly/1 s8JQAW>

. "Multidões queer: notas para uma política dos 'anormais"'. Revista Estudos Feministas, Florianópolis, v. 19, n. 1, p. 11-20, 2011.

RUBIN, Gayle; BUTLER, Judith. "Tráfico sexual - entrevista Gayle Rubin com Judith Butler". Cadernos Pagu, Campinas, n. 21, p. 157-209, 2003

SANDOVAL, Chela. "Dissident globalizations, emancipatory methods, social-erotics". In: CRUZMALAVÉ,Arnaldo; MANALANSAN IV, Martin F. (Ed.). Queer globalizations: citizenship and the afterlife of colonialism. New York: New York University Press, 2002.

SANDOVAL, Chela; LATORRE, Guisela. "Chicana/o artivism: Judy Baca's digital work with youth of color".EVERETT, Anna (Ed.). Learning race and ethnicity: youth and digital media. Cambridge: The MIT Press, 2008, p. 81-108.

TRINH, T. Minh-Ha; CHEN, Nancy N. "Speaking nearby: a conversation with Trinh T. Minh-Ha". Visual Anthropology Review, Malden, v. 8, n. 1, p. 82-91, Spring 1992.

TRINH, T. Minh-Ha. When the moon waxes red. New York: Routledge, 1991.

WASEM, Marcelo. "Passagens sonoras sobre autonomia, educação, ativismo, arte e sistemas". Polêm!ca, Rio de Janeiro, v. 11, n. 3, p. 10-20, 2012.

[Recebido em outubro de 2014 e aceito para publicação em novembro de 2014]

At the Margins of a Globalized Artivism: On the Borders of Mujeres Al Borde.

Abstract: The present article analyzes the interactions between two collectives of activists/ artists, the Queer Women of Color Media Arts Project (QWOCMAP), situated in the United States, and Mujeres Al Borde, situated in Colombia. By focusing on their interaction and addressing the audiovisual productions of the latter group, I discuss how they seek to create relationships between art, activism, audiovisual production, gender, sexualities, race/ethnicities, aiming to create transnational feminist coalitions. The article touches on the following topics: the creating process to developed a cinematic training program in partnership; reflects on the possibilities of thinking about activism and queer theories in Latin American context; and finally examines some of audiovisual productions of Mujeres Al Borde, trying to address what they call as their artivism, neologism that articulates art and activism. The focus here is on the ways in which these collectives are producing networks of transnational collaboration in global geopolitical dissidents' arenas, promoting social change and means of visual expression for LGBTQ communities, cultivating queer feminist social movements in the global north and global south.

Key Words: Micro-politics and LGBTQ/ Social Movements; Cinema, Art and Gender; Queer Latin American Artivism; Dissident Modes of Globalization. 